\title{
Mestrado Profissional em Educação: Teoria e Prática de Ensino - qualificação dos processos de educar na pesquisa da Educação Básica
}

\section{Professional Master's Degree in Education: Theory and Practice of Teaching - qualification of educational processes in Basic Education research}

\author{
Claudia Madruga Cunha ${ }^{1}$ \\ Neila Tonin Agranionih ${ }^{1}$
}

\begin{abstract}
RESUMO
$\mathrm{O}$ artigo analisa as dissertações produzidas pela primeira turma do Mestrado em Educação: Teoria e Prática de Ensino, da Universidade Federal de Paraná (UFPR, Brasil), destacando a construção da identidade deste Programa de formação de professores. Consideramos nessas propostas e resultados de pesquisa possíveis contribuições à realidade escolar que qualifiquem os objetivos do Programa. A partir da análise documental das 19 dissertações defendidas em 2015 pela primeira turma de mestrandos, catalogadas no acervo digital da Biblioteca da UFPR, buscamos encontrar os efeitos da instrumentalização da pesquisa ofertada pelo Programa, a capacidade de reflexividade, de autonomia, de elucidação da própria experiência e as possíveis intervenções nos contextos profissionais dos seus autores. As dissertações foram agrupadas em três eixos temáticos: o primeiro analisa experiências possíveis em um campo; o segundo analisa os instrumentos que vêm de fora da área; o terceiro analisa o meio. Nos estudos concluídos podemos localizar: i) tendências a explorar a experiência na busca de contribuir para o próprio campo; ii) tendências a privilegiar a tecnologia para a inovação da prática;
\end{abstract}

DOI: $10.1590 / 0104-4060.49807$

1 Universidade Federal do Paraná. Programa de Pós-Graduação - Mestrado Profissional: Teoria e Prática de Ensino. Setor de Educação. Curitiba, Paraná, Brasil. Rua General Carneiro, ${ }^{\circ}$ 460. CEP: 80060-150.E-mails: cmadrugacunha@gmail.com e ntagranionih@gmail.com 
iii) tendências a problematizar o meio escolar como efeito e contraefeito ao desenvolvimento do profissional e às condições da sua profissionalidade.

Palavras-chave: Mestrado Profissional; teoria e prática de ensino; pesquisa da experiência; prática docente.

\begin{abstract}
This article analyses dissertations produced by the first class of the Master's Program in Education: Theory and Practice of Teaching from Universidade Federal de Paraná (UFPR, Brazil), emphasizing the identity construction of this teacher education program. We considered these proposals and the research results as possible contributions to the school reality that qualify the goals of the Program. On the basis of documentary analysis of the 19 dissertations defended in 2015 by the first class of master students, which are catalogued in the digital collection of the UFPR Library, we looked for the effects of the research instrumentation offered by the Program, the capacity of reflection, autonomy, elucidation of own experiences and possible interventions in the authors' professional contexts. We grouped dissertations in three thematic axes: the first analyses possible experiences in a field; the second analyses instruments from outside the field; the third analyses the environment. In the concluded studies we could identify: i) tendencies to explore experience as a way to contribute to the field; ii) tendencies to privilege technology to innovate practice; iii) tendencies to problematize the school environment in its effects and counter-effects upon professional development and conditions of professionality.
\end{abstract}

Keywords: Professional master's degree; theory and practice of teaching; research on experience; teaching practice.

\title{
Introdução
}

Os mestrados profissionalizantes tendem a buscar sua identidade na produção de conhecimento em torno de um objeto comum - a qualificação profissional da prática docente - ao qual deverão se debruçar os estudos e as pesquisas no espaço formativo que os acolhe, conforme Parecer do Conselho Nacional de Educação. (BRASIL, 2009, p. 1). Nesse contexto, a qualidade do desenvolvimento profissional buscado nesse modelo de formação, por um lado, tende a homogeneizar aspectos de uma produção de conhecimento e, por outro, a singularizá-la quando tenciona, nesse processo, uma especificidade própria, a do exercício da docência. 
Ou seja, o empenho por uma formação de profissionais que qualifique a prática profissional no compromisso com a apropriação e a aplicação de conhecimentos por meio de rigor metodológico e científico garantida pelo Art. $3^{\circ} \mathrm{da}$ Portaria Normativa/Ministério da Educação (MEC) nº 17, de 28 de dezembro de 2009, tende a definir o Mestrado Profissional como modalidade de formação pós-graduada que capacita uma dada prática profissional. (BRASIL, 2009, p. 2). Tal qualificação voltada às práticas docentes, já existentes, se refere a articular experiências vividas nas escolas a estudos, investigação e pesquisa, fazendo destes últimos instrumentos de mudança dessa realidade, quando dão vazão às potencialidades, criatividades, possibilidades instrumentais, lutas diárias enfrentadas.

Nesse sentido, fica claro que o objetivo do Mestrado Profissional em Educação, especialmente do Mestrado Profissional: Teoria e Prática de Ensino da Universidade Federal do Paraná, como outros programas com esse formato, vem a se constituir em algo mobilizador da formação de profissionais-educadores-pesquisadores e não apenas de técnico-profissionais nos meandros dos processos educativos, especialmente, ao se tratar da Educação Básica, como torna claro o Relatório do Fórum de Coordenadores de Programas de Pós-Graduação na área da Educação (FORPRED), realizado em Goiânia, em 29 de setembro de 2013. (FORPRED, 2013, p. 4).

Logo, a identidade que os Mestrados Profissionais em Educação vêm moldando caracteriza-se pela formação voltada para a prática profissional e para a possibilidade de incorporar a essa prática inovações fundamentadas em pesquisas científicas, analises teóricas e práticas capazes de resolver problemas peculiares no ambiente escolar, promovendo avanços. O que implica assumir o compromisso com um processo de formação no qual não apenas a universidade se aproxima da escola básica, tencionando por aí os elos entre a formação inicial e continuada; também, se fortalecem as expectativas que fazem avançar a problematização entre a teoria e a prática, dicotomia que é foco dos investimentos em estudo e pesquisa para a aquisição de novos recursos para atuar na Educação Básica.

O estudo que aqui se apresenta traz algo do que Giroux (1997) já na década de noventa defendia, a capacidade de formar professores como "intelectuais", atores capazes de se apropriar, apreender e desenvolver conteúdos necessários às suas práticas pedagógicas. Pensando na autonomia que a pesquisa pode agregar ao professor que estuda a própria prática, Contreras (2012) faz avançar a perspectiva anterior quando diz que estes profissionais se sensibilizam atualmente com os efeitos dos conteúdos e das práticas de ensino que já não se reduzem à sala de aula, mas se expandem ao contexto social, cultural e político. Esse olhar retroativo à experiência do que acontece na escola não se refere somente a esse 
meio, provoca novos sentidos da própria docência. (CONTRERAS; PÉREZ DE LARA, 2010).

Em contrapartida, como analisa Cunha (2013, p. 11), “[...] o reconhecimento do trabalho docente como fonte de saberes e da complexidade da docência, sempre atingida por contingências contextuais" pode derivar numa captura de ação fugaz. Entende a autora que é preciso reconhecer " [...] o professor como sujeito epistêmico, que vai reconfigurando seus saberes em função dos desafios profissionais que a prática lhe impõe. É possível discutir a ideia de uma epistemologia da prática que não se identifique com um praticismo inconsequente". (CUNHA, 2013, p. 13). Nesse mesmo sentido, Vieira (2014) diz que tem se deslocado o núcleo da pedagogia da formação para o terreno da ação profissional, o que implica em um movimento de autenticação da teoria na prática.

Diante desse contexto, neste artigo, buscamos analisar as 19 dissertações produzidas pela primeira turma do Mestrado em Educação: Teoria e Prática de Ensino da Universidade Federal de Paraná (UFPR, Brasil), defendidas em 2015, e catalogadas no acervo digital da Biblioteca da UFPR. Essa formação de nível superior, na construção de seu processo de formação docente, tem buscado fortalecer a profissionalização docente incentivando a capacidade de aprendizagem do professor; tendo por foco uma pesquisa da prática docente, impulsiona um olhar para além dela, fazendo desse horizonte entre a teoria e a prática seu campo de diferenciação ou identificação de seus objetivos.

Para além dos autores já citados, são inúmeros os que na atualidade se debruçam sobre a importância da pesquisa na formação docente. Selecionamos alguns, para dar suporte a essa análise das dissertações defendidas em 2015, nas quais se busca identificar os processos investigativos explicitados e os seguintes elementos: temas que se autorizam a questionamento intelectual e crítico (GIROUX, 1997; STENHOUSE, 2007; ELLIOTT, 1998; ZEICHNER, 2002); o que problematizam (a partir de) amostras de sua autonomia profissional (STENHOUSE, 2007; CONTRERAS, 2012; NÓVOA, 2004)?; como elucidam a própria experiência e sensibilizam para representações da identidade e da profissionalidade docentes (CONTRERAS; PÉREZ DE LARA, 2010)? Parafraseando Vieira (2014), o que estes estudos desenham tende a articular pressupostos tanto de uma formação reflexiva como os de uma pedagogia para autonomia profissional. O estudo e a pesquisa da própria prática ampliam a formação para a docência, como diz Cunha (2013), desdobrando a relação entre escola e universidade. 


\section{Contexto e análise da produção docente no Mestrado: Teoria e Prática de Ensino}

O Mestrado Profissional em Educação: Teoria e Prática de Ensino, implementado na Universidade Federal do Paraná - Setor de Educação, em 2013, se propõe a dar conta das características que o definem como "profissional" e assume o compromisso de

[...] ofertar uma formação que se dedique ao aprofundamento e problematização das questões cotidianas da escola a partir da análise de práticas concretas, dos valores difundidos na sala de aula, de ideias emergentes da práxis docente e de novos caminhos possíveis rumo ao ideário educativo-escolar. (PPGE/MP, 2013, p. 11).

Caracteriza como elemento marcante de sua identidade o fortalecimento da formação de profissionais da Educação Básica que atuam nas redes públicas formando para e pela pesquisa. Neste sentido, mantém em seus editais de seleção a prioridade de acesso para professores e pedagogos que atuam na Educação Básica e estabelece como foco de pesquisa a investigação das questões entre prática e teoria.

A formação proposta pelo Mestrado em Teoria e Prática de Ensino, em consonância com o que os estudiosos do campo de formação docente vêm apontando como recurso para enfrentar dificuldades encontradas na formação inicial e continuada de professores, aposta na pesquisa como ferramenta de transformação da prática docente.

A análise das 19 dissertações produzidas pela primeira turma do Mestrado permitiu identificar três eixos temáticos que correspondem ao enfoque central da produção de conhecimento e que dizem respeito ao objeto de estudo elegido por seus autores, são eles: exploração de práticas em busca da inovação no próprio campo; exploração da tecnologia para inovação da prática; problematização do papel e da identidade do profissional em educação no desenvolvimento das suas atividades.

Propomos destacar na leitura que abrevia estas produções de conhecimento como os professores que passaram por esse processo de formação continuada que oferta as ferramentas de pesquisa e da investigação puderam problematizar e intervir nas suas práticas escolares (ANDRÉ, 2016); bem como, realizam 
com esses trabalhos um registro das experiências, das práticas e das realidades do cotidiano escolar que tende a contribuir para a construção de novos olhares transversais entre formação inicial e contínua de professores. Apresenta-se abaixo o que trazem estes estudos.

\section{Eixo 1 - estudos que analisam experiências possíveis em um campo}

O primeiro grupo de dissertações, num total de seis, reinventou a prática a partir de novos conhecimentos, de nova conceptualização e de contextualização dos seus modos de ensinar e de aprender expandindo o próprio campo. Quanto ao problema construído, ao encaminhamento metodológico, às bases teóricas e às possíveis contribuições deste grupo de dissertações para a realidade escolar, pode-se observar:

a) Daniel (2015) investigou as dificuldades na aprendizagem da matemática nos anos iniciais do ensino fundamental e, sob o olhar interventor de uma pesquisa de campo, analisou a aprendizagem dos alunos do quarto ano em uma escola pública de ensino fundamental do município de Curitiba. Com esses referenciais apresentou análise qualitativa e quantitativa das atividades realizadas no período da investigação. Contribuiu com seu trabalho evidenciando que o ensino da matemática eficiente e interessante implica mudanças nas concepções e práticas dos professores; entendeu que é na análise das construções e dos erros dos alunos, na constante formação e na atualização teórica, que reside parte importante de um processo de novos conhecimentos para uma melhor intervenção nessa área;

b) Fidalgo (2015) propôs uma cartografia dos jogos cooperativos na qual essa prática ou modalidade aparece como meio de contraposição à lógica competitiva que rege o ensino das práticas corporais. Com o objetivo de fomentar outros sentidos para a experiência corporal, sendo supervisor dos estagiários da área de Educação Física inscritos no programa Programa Institucional de Bolsa de Iniciação à Docência (PIBID)/UFPR, organizou na cartografia com esses parceiros um conjunto de práticas que foi levado a turmas do nono ano de uma escola pública de Curitiba. Enfatizou novos potenciais educativos dos jogos cooperativos, tanto porque só os erros cometidos durante os jogos permitem estabelecer entre os(as) jogadores(as) e o(a) professor(a) em formação novos sentidos em relação à disciplina, quanto porque tal prática pode ser ferramenta para nova ética e estética das aulas de Educação Física;

c) Jochelavicius (2015) produziu um trabalho na disciplina de Artes Visuais voltado ao processo criativo de Hélio Leites por entender que este abre possibilidades para pensar ecosoficamente (criação da autora) a vida, a arte e a educação. Analisou a proposição de uma experiência que envolveu o mul- 
tiartista curitibano, que trabalha com objetos descartados. Tencionou a ideia do inutensílio ligada a uma estética existencial para desenvolver a noção de experiência numa estética educativa; trabalhou o conceito de experiência na docência e a noção de educação menor nesse mesmo contexto; quis demarcar, no que se refere ao ensino de artes, que em uma sociedade democrática se pode viver no dissenso sem o apelo a consensos, abrindo assim novas perspectivas ao trabalho com essa área nas escolas;

d) Martins (2015) trouxe a experiência de uma professora de Educação Física que utiliza a fabulação como modo ou meio de interagir com a infância nas aulas de Educação Física voltadas a crianças em fase de pré-alfabetização. A metodologia narrativa ligada à pesquisa qualitativa encontrou vazão associada à base teórica dos estudos sobre a infância. Fez uso de três narrativas nas quais desenvolve uma perspectiva autobiográfica da infância como acontecimento; cogitou que o paralelo entre infância e Educação Física se reflete em outro: a teoria e a prática. No encontro com a narrativa reconheceu em si a capacidade de fabulação e com essa ferramenta fez uma ponte que liga esses extremos que coabitam a escola;

e) Pereira (2015) problematizou a aprendizagem da língua portuguesa nas séries iniciais através de uma análise metodológica sustentada na concepção de alfabetização nas áreas da Psicologia da Educação e da Linguística. Fez pesquisa-ação com alunos da rede municipal de Curitiba, em que optou por uma microanálise das condições iniciais desses estudantes, no intuito de avançar no processo de aquisição do sistema de escrita alfabética. Problematizou o conceito de alfabetizar para concluir que essa ação é um processo complexo e trabalhoso. Os dados colhidos levaram-na a perceber que a escola é ainda o ambiente responsável pelo estímulo positivo e aferição de resultados na alfabetização;

f) Oliveira (2015) analisou os impactos na aprendizagem da leitura de textos de histórias em quadrinhos para o desenvolvimento da escrita. Desenvolveu uma abordagem qualitativa orientada pela pesquisa-ação com alunos de $3^{\circ}$ ano do ensino básico. $\mathrm{O}$ gênero histórias em quadrinhos como prática de leitura foi observado num processo que envolveu três momentos: diagnóstico, intervenções e, por último, análises das atividades desenvolvidas. Observou que a concepção de ensino, o planejamento e os instrumentos metodológicos utilizados pelo professor para fomentar a relação entre leitura de histórias em quadrinhos e práticas de escrita são seleção de estratégias e cuidado com o processo, que podem resultar em uma perspectiva dialógica do conhecimento.

Os autores encontram nos jogos cooperativos, na fabulação, nas histórias em quadrinhos, na análise de erros, na prática de reciclagem artística, possibilidades de enfrentamento dos desafios próprios da escola. Tais pesquisas ofereceram, com base no que diz Nóvoa (1992), condições para que assumis- 
sem a sua realidade escolar como objeto de pesquisa, de reflexão e de análise das práticas. Olhando para esse grupo de produções, se percebeu a tendência à exploração da experiência na busca de contribuir para o próprio campo; são experiências individuais que vão construindo por meio da pesquisa referenciais da própria área, fazendo eco ao que disseram outros autores. (GIROUX, 1997; STENHOUSE, 2007; ELLIOTT, 1998; ZEICHNER, 2002). Pode-se dizer que estes estudos buscaram novos saberes reinventando o próprio campo, associaram, pelo estudo, novos conceitos e novos valores às práticas já estabelecidas, ligadas à área de especificidade. Ao ampliarem o campo teórico de suas práticas, fizerem abordagens diferentes às atividades já existentes, expandiram o território de compreensão e, portanto, de significação em que essas se acolhem.

\section{Eixo 2 - estudos que analisam instrumentos de fora da área}

Esse segundo eixo buscou fora da área de formação recursos que ampliassem suas práticas ou as inovassem. Nesse grupo os investimentos se fizeram em utilizar tecnologias para exploração de novos saberes, no que se refere aos conteúdos e conceitos do próprio campo esses ficaram menos investidos. Com um total de seis dissertações, esse grupo fez uso da realidade virtual ou das tecnologias de informação para propor ferramentas didático-pedagógicas na sala de aula. A produção das dissertações teve as seguintes características:

g) Dalmarco (2015) desenvolveu aulas de Filosofia com alunos do Ensino Médio com o objetivo de conhecer e utilizar as Tecnologias da Informação e Comunicação (TICs) e suas ferramentas digitais. Incentivou o uso do Blog como ferramenta digital para armazenagem de dados e aprendizagem da disciplina. Utilizou a observação acompanhada como forma de pesquisa qualitativa. Com esse recurso planejou ações onde os estudantes deviam se perceber como usuários da $W E B$ e desenvolver propostas de cibercidadãos. Concluiu que ao propor a construção de um Blog de Filosofia para repositório de conteúdo, na ideia de integrar mídias como vídeos, textos e imagens e de aproximar a área do cotidiano dos estudantes, fez escolha por um caminho frágil, pois o não domínio de conteúdos e a imaturidade dos alunos dificultaram explorar melhor a proposta;

h) Aparecido de Oliveira (2015) se debruçou no processo de organização dos registros audiovisuais em portfólios como abordagem metodológica. Fez desses portfólios audiovisuais um material didático experimental para professores de Educação Infantil fazerem registros. Tomando esses instrumentos para avaliar e organizar novos recursos pedagógicos, concluiu, numa abordagem de pesquisa qualitativa de cunho descritivo e interpretativo, que os portfólios audiovisuais, na Educação Infantil, podem ser instrumento de caráter colaborativo e dialógico vindos a contribuir para a reflexão, o planejamento e a avaliação, 
produção de memória da própria criança e de seu processo de aprendizado na promoção de novos saberes;

i) Schubalski (2015) buscou formas de integrar as tecnologias à práxis educacional, quis, com a tecnologia, abordar a constituição do sujeito no foco da pedagogia crítica e reflexiva. Fez pesquisa qualitativa com uso de produção de documentários como recursos didáticos, tendo por parceiros um grupo de professores da rede estadual. Fundamentando-se em considerações crítico-reflexivas, fez da tecnologia no espaço educacional objeto investigativo. Percebeu conflitos e limites na relação entre uma abordagem pedagógica crítica e a simples adaptação aos recursos tecnológicos, na construção de documentários com grupo docente no objetivo de desenvolver processo de autoria e de coautoria;

j) Paschuini (2015) testou o aplicativo tradutor de Língua Portuguesa/ Libras em uma sala de surdos da Educação de Jovens e Adultos na implementação de uma sequência didática com Tecnologias Digitais de Informação e Comunicação. Objetivou auxiliar o letramento digital e favorecer a escrita e outras práticas educativas em que o aluno surdo pode ser reconhecido em sua individualidade e meio sociocultural. Com uso da abordagem qualitativa, fez observação total e participante. Concluiu que a infoinclusão dos alunos surdos com $o$ Hand Talk encontra limites, não pode substituir o professor e ainda se mostra um instrumento que serve de suporte ao tradutor de língua de libras, aquele que ouve; logo, aplicativos que atendem melhor à cultura surda são recursos tecnológicos ainda por desenvolver;

k) Buch (2015) utilizou o moodle para o ensino de língua japonesa hiragana e katakana a alunos não nikkei ou não descendentes de japoneses, em um Colégio Técnico do interior do Paraná. Tencionou o ensinar e o aprender a língua japonesa hajimemasho, seus principais alfabetos hiragana e katakana, em um período de tempo de 24 dias. Experimentou um método de curso on-line de língua japonesa cujo objetivo não foi a fluência na língua, mas sim a decodificação de suas estruturas básicas. Verificou que através do moodle os estudantes acessaram alguns conhecimentos básicos para conhecer e compreender a língua e a cultura japonesa, aprenderam alguns conceitos básicos da língua japonesa;

1) Lima (2015) testou possibilidades da fotografia no ambiente escolar em um trabalho com estudantes do ensino básico quando elaborou uma sequência didática, partindo dos documentos oficiais que desafiam a construção da identidade e autonomia da criança em idade pré-escolar. Organizou uma sequência didática em que as crianças tiraram selfies, fotos de si, dos colegas e da professora; e, por meio de suas fotografias, mostrou como a cultura interage com as tecnologias na sala de aula. Concluiu, ao utilizar a fotografia com as crianças de nível pré-escolar II, que tal técnica pode explorar a construção da identidade e da autonomia. 
As dissertações desse eixo se aproximaram da tecnologia investindo mais em instrumentos para diferenciar o cotidiano das práticas de sala de aula. Quase todas foram produtoras de uma análise redutiva e técnica do próprio campo epistemológico, nas tendências de privilegiar a tecnologia para inovação da prática. Por outro lado, assinalaram possibilidades de uso das tecnologias como alternativas ao ensino, sem deixar de abordar seus limites, contribuindo para reafirmar a necessidade de ampliar reflexões sobre novos instrumentos e técnicas. (ZEICHNER, 2002; CONTRERAS, 2012; NÓVOA, 2004). Esse grupo faz pensar no que disse Stenhouse (2007, p. 59), que “[...] a investigação só pode ser adequadamente aplicada a educação quando desenvolve uma teoria que pode ser aplicada pelos professores em aula". Mais que isso seria aceitar que existem discursos e práticas que se utilizam de novos instrumentos por uma via imposta do novo, essa novidade não refletida em sua consequência e finalidade na prática tende a permanecer à margem da consciência profissional.

\section{Eixo 3 - estudos que analisam o meio ou a classe docente}

Por fim, o terceiro grupo de dissertações integra sete estudos ligados à profissionalidade e à identidade dos profissionais da Educação Básica. Estão diretamente ligados às práticas de sala de aula, investem em contextualizar as condições da docência no seu aspecto estrutural, funcional e psicossocial. Tendo por foco a percepção da profissionalidade propuseram entrevistas aos colegas professores ou à própria classe. Nos dados que obtiveram se pode evidenciar que o "[...] que os valores educativos significam é algo aberto a interpretação e ao julgamento na busca de situações concretas". (CONTRERAS, 2012, p. 129). Nesse sentido, nem toda pré-interpretação dos fatos e dos contextos foi apenas conformada. Nesse grupo de estudos se destacou:

m) Franco (2015) trabalhou a relação entre Políticas de Educação Especial Inclusiva e as práticas docentes, estas últimas nomeou de potencialidades ou possibilidades, referindo à capacidade de diagnóstico das profissionais das escolas públicas de ensino regular e dos Centros Municipais de Atendimento Especializado (CMAEs) de Curitiba. Fez uso da cartografia para sobrepor política e prática profissional. Para entendimento das práticas de diagnóstico realizou entrevistas com profissionais, trouxe à deriva que existem muitas lacunas na forma como esse grupo interpreta e encaminha procedimentos educativos, o que tende a fragmentar a aprendizagem dos estudantes e em alguns casos a excluí-los no próprio processo de inclusão;

n) Xavier (2015) promoveu reflexões sobre a relação entre a violência estrutural em que estão submetidos os professores e o consequente adoecimento docente. Utilizou ferramentas da pesquisa qualitativa quando aplicou questionário semies- 
truturado contendo perguntas abertas e fechadas a dois professores aposentados em decorrência de doenças ocupacionais, os quais foram escolhidos após ampla divulgação na página da Associação de Professores do Paraná (APP/Sindicato). Sustentando-se nos teóricos da complexidade, pode concluir como necessária uma formação inicial voltada ao reconhecimento das questões socioeducativas, pois vê nessa ação um modo de evitar processualmente o adoecimento dos professores;

o) Araujo (2015) buscou compreender a relação existente entre a identidade do professor e o uso das tecnologias e mídias digitais, nas escolas da rede municipal de ensino do município de Araucária. Numa abordagem de cunho qualitativo fez uma investigação em três etapas: coleta de dados com 20 professores; coleta de dados com 218 respondentes de questionários on-line; seleção de 7 professores para aprofundar dados obtidos no estudo exploratório. $\mathrm{Na}$ análise dos dados orientada pela teoria da complexidade concluiu que a identidade docente é um fenômeno multidimensional e, embora a cultura digital venha modificando as práticas profissionais, as circunstâncias e os fatores aferidos propõem evidências que não garantem uma uniformidade nos modos subjetivos de utilizar, de integrar e de se apropriar das tecnologias;

p) Janz (2015) investigou a mediação dos pedagogos na formação continuada de professores que atuam na Educação de Jovens e Adultos (EJA), especialmente, em sete Centros Estaduais de Educação Básica para Jovens e Adultos (CEEBJAs) de Curitiba. Quis conhecer o reconhecimento e a legitimidade do pedagogo escolar como o profissional que organiza e dá sustentação ao processo de ensino e de aprendizagem, entendendo-o como alguém capaz de articular os espaços de reflexão sobre a prática. Entrevistou 13 de um universo de 39. Ao final, concluiu que para evitar uma visão reducionista do processo pedagógico, a formação dos próprios pedagogos dos CEEBJAs de Curitiba devia ser mais debatida pelos próprios profissionais que os compõem, no intuito de atender às especificidades do ensino de jovens, adultos e idosos;

q) Davel (2015) averiguou as possibilidades e os limites para o trabalho com o ensino de língua inglesa nos anos finais do Ensino Fundamental na Rede Municipal de Curitiba utilizando-se da metodologia qualitativa da análise do discurso, que tem por base a linha francesa. Propôs questionário a 22 professores de inglês, de onde analisou que o termo "língua adicional" está mais próximo das relações atuais entre língua inglesa, cultura e escola. Também passou a compreender que os conhecimentos mobilizados na prática e no discurso pedagógico no ensino da língua inglesa têm apontado para possibilidades diversas e não homogeneidade, na construção de relações de sentido e de significados que resgatam o conhecimento prévio do aluno;

r) Buzatto (2015), tendo por foco a diferença e a identidade cultural, quis verificar a ação do pedagogo como interventor nos casos de preconceitos 
étnicorraciais e de orientação sexual. Utilizou a pesquisa-ação e os estudos multiculturais para interpretar como a Equipe Multidisciplinar de um colégio da rede estadual de ensino na cidade de Curitiba tem se revelado frente ao estudo dos preconceitos e atitudes discriminatórias, intervindo ou não com esses temas nos processos formativos. Concluiu, após análise de dados, que a inserção dos temas que se referem a preconceitos étnicorraciais e à orientação sexual ligados à diversidade cultural, na formação continuada de docentes e pedagogo/as, precisa percorrer um longo caminho na busca de efetivar uma escola mais humana e justa;

s) Chudzij (2015) acercou-se da larga tradição do município em relação à ampliação das jornadas escolares para entender o papel desempenhado pelo pedagogo nas escolas municipais de Curitiba de tempo integral, desde o processo de implementação aos dias de hoje. No uso do aporte qualitativo aplicou questionário a pedagogos de sete escolas da rede municipal de ensino, orientado por quatro eixos: formação inicial e continuada; carreira profissional; rotinas escolares; avaliação do papel do pedagogo na escola. Nos dados colhidos pode perceber a necessidade de resgatar o debate da identidade do pedagogo da escola de tempo integral, uma vez que o ensino de tempo alongado promove mudanças, novas atribuições, que duplicam as intervenções a problemas e conflitos interpessoais no interior da escola.

Esse último grupo de estudos mostra inquietações psicossociais que se referem à identidade e ao papel do profissional educador, demandas presentes na educação. Ao analisar a educação integral, a educação especial, as fronteiras entre a identidade profissional e cultural, a educação de jovens e adultos, esse grupo contribuiu no sentido de se dispor a uma ação de intervenção de enfrentamento dessas demandas, na tendência a problematizar o meio escolar como efeito e contraefeito ao desenvolvimento do profissional e as condições da sua profissionalidade. Pode-se dizer, conforme Cunha (2013, p. 7), que "[...] a perspectiva de estudar o professor como sujeito concreto da ação pedagógica contribuiu para entendê-lo na sua constituição técnica, pessoal e profissional". Mas esse desdobramento precisa ainda ganhar espaço nos estudos que relacionam educação e trabalho.

\section{Analisando os três eixos no seu conjunto}

Tomar ciência do que foi proposto nessas dissertações fez refletir sobre os problemas nelas apontados, desenvolvidos com maior ou menor eficácia pelo 
estudo e pela pesquisa, e conduz, ao mesmo tempo, a que se considere claros os avanços individuais, profissionais e pessoais, vividos singularmente com maior ou menor amadurecimento nesse processo de formação. Os grupos de temas e de modos de conduzir a investigação com os próprios estudantes, com uso das tecnologias e informação e comunicação, com os colegas docentes e pedagogos, vão oportunizando uma tonalidade a esta formação, a construção de sua identidade enquanto mestrado profissional.

Por um lado, repensando o início deste texto, quanto aos encaminhamentos, às regulações ou enquadramentos dos estudos aos modelos de pesquisa, o que se observou foi que os procedimentos utilizados permitem pensar que está se fazendo um entendimento muito amplo sobre o que é pesquisa qualitativa em educação. Não que as pesquisas desenvolvidas utilizassem outra metodologia, não se vê a sustentação de outro caminho. Também não se vê a defesa dos instrumentos e dos encaminhamentos metodológicos disponíveis, o que na maioria das vezes acaba por restringir as prioridades desta pesquisa. Os procedimentos que a acompanham e a desenvolvem, assim como os instrumentos que a produzem, na maioria das vezes apenas nomeados, sem serem desdobrados ou defendidos pelo trabalho conceitual e argumentativo, a reduzem a nomeações técnicas.

Por outro lado, as pesquisas qualitativas podem ser abordadas nas suas diferentes vertentes e dizem respeito a diferentes tendências de estudo, as pesquisas do tipo pesquisa-ação, pesquisa participante, fenomenológicas, histórias de vida, etnográficas aparecem sob determinado contexto na formação de professores. Esse tipo de pesquisa sob a influência dos estudos culturais e da sociologia, no seu uso, vem assegurar um modo de expressão que rompe algumas fronteiras da própria concepção de produção de conhecimento. (CUNHA, 2013). Por isso aparece junto ao contexto em que os movimentos reivindicam maior autonomia dos coletivos institucionais e protagoniza um apelo por experiências inovadoras, deixando em aberto um espaço de revisão constante, através de pesquisa, do desenvolvimento das práticas e dos modos de se exercer a profissionalização docente. (CONTRERAS, 2012; VIEIRA, 2014).

No que se refere à aproximação entre escola e universidade, conforme Ludke (2014, p. 54), que parafraseia Elliott, que “[...] toda a inspiração da pesquisa em educação [...] deve vir dos problemas vividos pelo profissional envolvido na prática educacional, e não dos investigadores mergulhados nos seus respectivos campos de pesquisa". Ainda na mesma perspectiva se pondera, com a autora, sobre as possíveis intervenções da pesquisa na relação entre teoria e prática no trabalho e na formação de professores, que "[...] a primeira realidade a ser modificada por qualquer pesquisa é a do próprio pesquisador. Ele se modifica, inquestionavelmente, a cada pesquisa que realiza, pela ação mesma da pesquisa e pelo conhecimento que eventualmente constrói”. (LUDKE, 2014, p. 55). 


\section{Conclusão}

Os olhares sobre o contexto escolar, sobre esse meio onde se desenvolve e se expõe à teste a qualificação da profissionalidade do professor, almejada pelo Mestrado Profissional: Teoria e Prática de Ensino, diferenciam condições de atuação profissional e as experiências vividas. Tais visões ampliam a sala de aula, a escola e a comunidade a que essa pertence no âmbito sociocultural e político. O que o primeiro grupo de dissertações defendidas mostra, no conjunto, contribui com o registro das realidades escolares, proporciona documentação das práticas que vêm se realizando no interior das salas de aula, atua como diagnósticos para as questões que vêm sendo vividas e experienciadas no espaço escolar e para além dele, na transversalidade dos efeitos que esse meio produz e absorve. (CONTRERAS, 2012).

A leitura das conclusões dos estudos demonstra um acréscimo à profissionalidade dos professores autores das dissertações analisadas. Em muitas delas é possível ler o registro reflexivo e sincero dos fracassos das expectativas, os avanços nos modos de refletir seus contextos, a ampliação dos seus horizontes teóricos, os sucessos e os fracassos nas formas encontradas para intervenção em suas realidades por meio da pesquisa. Anotam no todo acrescentamentos para a qualificação pretendida pelo Programa de Pós-Graduação em Educação: Teoria e Prática de Ensino. Nos estudos concluídos se pode localizar: i) tendências à exploração da experiência na busca de contribuir para o próprio campo; ii) tendências a privilegiar a tecnologia para a inovação da prática; iii) tendência a problematizar o meio escolar como efeito e contraefeito ao desenvolvimento do profissional e às condições da profissionalidade.

Essa qualificação docente ao mesmo tempo em que desenvolve as características da identidade questiona seus primeiros produtos, seus limites e seu alcance como instrumentos de intervenção na Educação Básica. Consideramos, no entanto, que a reflexão sobre a própria prática constitui um dos desafios a ser enfrentado pelo Mestrado em Educação: Teoria e Prática de Ensino, na perspectiva de formar professores pesquisadores, reflexivos, autônomos, capazes de promover mudanças através dos estudos e das pesquisas a partir da reflexão da própria experiência, da prática e do meio para construção de processos emancipatórios que validem o ensinar e o aprender. 


\section{REFERÊNCIAS}

ANDRÉ, M. A formação do pesquisador da prática pedagógica. Revista Multidisciplinar Plurais, Salvador, v. 1, n. 1, p. 30-41, jan./abr. 2016.

BRASIL. Ministério da Educação. Portaria Normativa $n^{\circ} 17$, de 28 de dezembro de 2009. Dispõe sobre o mestrado profissional no âmbito da Fundação Coordenação de Aperfeiçoamento de Pessoal de Nível Superior - CAPES. Disponível em: $<$ https:// www.capes.gov.br/images/stories/download/legislacao/PortariaNormativa_17MP.pdf>. Acesso em: 10 set. 2016.

CONTRERAS, J. Autonomia de professores. 2. ed. São Paulo: Cortez, 2012.

CONTRERAS, J.; PÉREZ DE LARA, N. La experiência y la investigación educativa. In: CONTRERAS, J.; PÉREZ DE LARA, N. (Org.). Investigar a experiência educativa. Madrid: Morata, 2010. p. 21-87.

CUNHA, M. A. O tema da formação de professores: trajetórias e tendências do campo na pesquisa e na ação. Revista Educação e Pesquisa, São Paulo: USP, n. 3, p. 609-625, jul./set. 2013.

ELLIOTT, J. Recolocando a pesquisa-ação em seu lugar original e próprio. In: GERALDI, C.; FIORENTINI, D.; PEREIRA, E. M. de A. (Org.). Cartografias do trabalho docente: professor(a) pesquisador(a). Campinas: Mercado de Letras, 1998.

FÓRUM NACIONAL DE COORDENADORES DE PROGRAMAS DE PÓS-GRADUAÇÃO EM EDUCAÇÃO (FORPRED). Relatório das condições e perspectivas dos mestrados profissionais na área de educação. Goiânia, 2013. Disponível em: <http:// www.anped.org.br/sites/default/files/relatorio_comissao_forpred_2013.pdf $>$. Acesso em: 10 set. 2016.

GIROUX, H. A. Os professores como intelectuais. Porto Alegre: Artmed Editora, 1997.

LUDKE, M. O papel da pesquisa na formação de professores. In: OLIVEIRA, M. R. (Org.). Professor, formação, saberes e problemas. Porto: Porto Editora, 2014.

NÓVOA, A. Formação de professores e profissão docente. In: NÓVOA, A. (Org.). Os professores e sua formação. Lisboa: Dom Quixote, 1992.

NÓVOA, A. Educação e formação ao longo da vida: entrevista. São Paulo: CRE Mario Covas. Entrevista concedida por e-mail em out. 2004. Disponível em: <http:www. crmariocovas.sp.gov.br>. Acesso em: 10 set. 2016.

PROGRAMA DE POS-GRADUAÇÃO EM EDUCAÇÃO: TEORIA E PRÁTICA DE ENSINO (PPGE/MP). 2013. Disponível em: <http://www.ppge-mp.ufpr.br/2013>. Acesso em: 10 set. 2016.

STENHOUSE, L. La investigación como base de la ensenanza. Madrid: Morata, 2007. 
VIEIRA, F. (Org.). Quando os professores investigam a pedagogia. Em busca de uma educação mais democrática. Ramada: Edições Pedago, 2014.

ZEICHNER, K. Formação de professores reflexivos para uma educação centrada no aprendiz: possibilidades e contradições. In: ESTEBAN, M. T.; ZACCUR, E. (Org.). Professora-pesquisadora - uma prática em construção. Rio de Janeiro: DP\&A, 2002.

Texto recebido em 17 de novembro de 2016. Texto aprovado em 18 de dezembro de 2016.

\section{Apêndice}

Lista de dissertações defendidas no PPGE, Mestrado Profissional Teoria e Prática de Ensino, Universidade Federal do Paraná, no ano de 2015. Disponíveis em: <acervodigital.ufpr.br>. Acesso em: 10 set. 2016.

APARECIDO DE OLIVEIRA, R. Portfólios audiovisuais - concepção de avaliação formativa na educação infantil.

ARAUJO, M. T. M. A identidade do professor que utiliza as tecnologias e midias digitais na sua prática pedagógica.

BUCH, V. M. O uso do moodle para o ensino de língua japonesa básica hiragana ひ らがな e katakana カタカナ a alunos não-nikkei.

BUZATTO, O. R. Análise da formação dos/as professores/as diante da diversidade cultural na escola básica: novas dimensões do trabalho do/as pedagogo/as.

CHUDZIJ, V. L. F. O papel e a identidade dos pedagogos das escolas de educação integral no município de Curitiba.

DALMARCO, P. A realidade pedagógica analógica: o uso de blog nas aulas de filosofia.

DANIEL, J. E. S. Aprendizagem matemática nos anos iniciais do ensino fundamental.

DAVEL, M. A. O ensino de língua inglesa na rede municipal de Curitiba: o discurso dos professores sobre suas possibilidades e limites.

FRANCO, L. R. Cartografias das potências e das potencialidades em Educação Especial - um diálogo entre as políticas e as práticas.

FIDALGO, M. Cartografia dos jogos cooperativos nas aulas de educação física.

JANZ, L. A. T. Legitimidade e reconhecimento do papel do pedagogo no processo de formação continuada dos professores da educação de jovens e adultos. 
JOCHELAVICIUS, G. F. C. Poética do inutensilio e experiência: tramas de uma educação menor.

LIMA, D. A. Num mundo de selfies: a fotografia como recurso pedagógico para educação infantil.

MARTINS, K. C. P. Três narrativas da infância - a fabulação nas aulas de educação física das séries iniciais.

OLIVEIRA, H. R. A. A história em quadrinhos e suas facetas: práticas de leitura no $3^{\circ}$ ano do ensino fundamental.

PASCHUINI, E. A. A infoinclusão de alunos surdos na educação de jovens e adultos utilizando o aplicativo hand talk em sala de aula.

PEREIRA, A. T. Oralidade, leitura e escrita no domínio do sistema da escrita alfabética.

SCHUBALSKI, J. A. Práxis educacional em trabalho com documentários.

XAVIER, A. Violência estrutural no trabalho docente. 
